\title{
Are labor unions important for business cycle fluctuations? Lessons from Bulgaria
}

\author{
Aleksandar Vasilev ${ }^{1}$ \\ Received: 19 February 2019 / Revised: 16 August 2019 / Accepted: 20 August 2019 / \\ Published online: 9 September 2019 \\ (C) The Author(s) 2019
}

\begin{abstract}
In this paper, we investigate the quantitative importance of collective bargaining agreements for the observed fluctuations in Bulgarian labor markets. Following Maffezzoli (Rev Econ Dyn 4:860-892, 2001), we introduce a monopoly union into a real-business-cycle model with government sector. We calibrate the model to Bulgarian data for the period following the introduction of the currency board arrangement (1999-2018), and compare and contrast it to a model without unions. We find that the sequential bargaining procedure between the monopoly union and the standin firm produces an important internal propagation mechanism within the theoretical setup, which allows the monopoly model to fit data better than the alternative framework with perfectly-competitive labor markets.
\end{abstract}

Keywords Business cycles · General equilibrium - Labor unions · Indivisible labor · Involuntary unemployment

JEL Classification E32 $\cdot$ E24 $\cdot$ J23 $\cdot$ J51

\section{Introduction and motivation}

The standard real-business-cycle (RBC) model, featuring a perfectly-competitive labor market, e.g. Kydland and Prescott (1982) and Long and Plosser (1983), was shown to be unable to capture the dynamics in the labor markets in the US. For Bulgaria, Vasilev (2009) documented a similar failure for the model to match the observed wage- and employment fluctuations. As a general rule, most of those earlier studies in the literature have tried to explained the mismatch with a modeling choice based on perfect information and market-clearing, and thus involuntary unemployment is absent from the framework. Bulgaria, however, along with many other Eastern European countries, registers a significant amount of involuntary

Aleksandar Vasilev

avasilev@lincoln.ac.uk

1 Lincoln International Business School, Lincoln, UK 


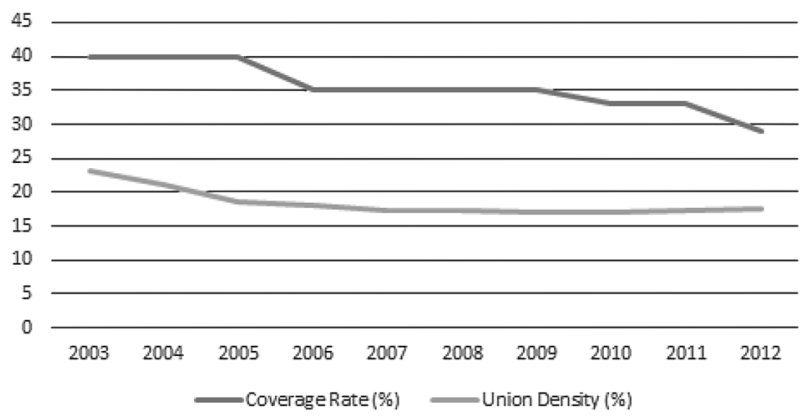

Fig. 1 Union density and coverage rates in Bulgaria. Source: European Trade Union Institute (2018)

unemployment, which was due to the process of structural transformation in the economy. In other words, being out of job in such an environment is clearly not an optimal choice, as it represents a waste of non-storable labor resources.

Modeling correctly unemployment as an inefficient outcome requires researchers to depart from the Walrasian (market-clearing) view of labor markets. In other words, involuntary unemployment can only appear in a model setup where certain labor market imperfections that are present in the economy are also modeled. One typical example of labor market frictions is the prevalence of collective bargaining arrangements between labor unions and firms in the economy. Figure 1 below documents their quantitative importance in Bulgaria.

The results above suggest that those arrangements need to be taken seriously when modeling labor markets in Bulgaria. In particular, despite the fall in the overall unionization rate, measured by "union density", over the period covered, and the decentralization of collective bargaining to individual firm's level, such collective agreements are still important on the aggregate level-after all, over a third of employed workers in Bulgaria are covered by some form of collective agreement. Moreover, given that such agreements usually take place in the largest firms (and in the public sector), the remaining firms generally follow closely those agreements in the non-unionized sectors as well. For example, Paskaleva (2016) demonstrates that the fact that real wages in Bulgaria are downward rigid is exactly due to the collective agreements in place, which prohibit cuts in base wages, and only allow for temporary wage freezes. ${ }^{1}$ In addition, such legal restrictions in place mean that adjusting labor costs needs to happen mostly through employment reductions. ${ }^{2}$ Therefore, real rigidities in the labor market along those lines could potentially generate a qualitatively important propagation mechanism in the model, which, in addition to making the setup more realistic, can help the artificial economy match observed business cycle fluctuations better, especially along the labor market dimension.

\footnotetext{
${ }^{1}$ Lozev et al. (2011) also document downward real wage rigidity in Bulgaria. He finds it to be lower than the rigidity in the other EU member states.

2 Therefore, the very presence of collective bargaining may also generate involuntary unemployment.
} 
We take the empirical findings presented in Fig. 1 above as an empirical regularity, which in turn motivates our modeling approach. In this paper, we take the presence of unions in the setup as an important ingredient in the theoretical framework. We then adapt the standard Dynamic Stochastic General Equilibrium (DSGE) model by augmenting it with a plausible mechanism of collective wage bargaining procedure. This modeling approach deviates from spot wage contracting, and instead emphasize institutional labor arrangement. Furthermore, the alternative mechanism of wage contracting considered here is also based on non-Walrasian settings, which are promising area of research, as pointed above, and in Blanchard and Fischer (1989).

We follow Maffezzoli (2001), and introduce monopoly labor unions in the general-equilibrium setup, in order to study their quantitative implications for business cycle fluctuations in Bulgaria. ${ }^{3}$ In contrast to Vasilev (2015c), who introduces a union in the government sector only, here the union is to be interpreted as a privatesector union, as we do not model public employment explicitly. ${ }^{4}$ Another novelty relative to the setup in Maffezzoli (2001) is that we make the reservation wage in the monopoly-union objective function conditional on the total factor productivity, which, aside from making the model more realistic, further helps to improve the model's performance vis-a-vis data. In addition, we also discuss the business cycle properties of real wages and employment, their auto-correlations, and the dynamic correlation between employment and the wage rate, which is missing from Maffezzoli (2001).

We then proceed to calibrate the model to Bulgarian data after the introduction of the currency board arrangement, which was a period of aggregate stability, and study the impulse responses of aggregate variables in the face of exogenous technological shocks. We compare and contrast the monopoly-union model against a framework without unions, and more specifically to the Rogerson and Wright (1988) setup with indivisible labor and inseparable utility in consumption and leisure. The latter was chosen, as it was shown in King and Rebelo (2000) to dominate the standard model with divisible hours, while retaining the perfectly-competitive labor markets assumption. Also, the indivisible labor model is more realistic, when compared to the setup with divisible labor, Vasilev (2009), as in Bulgaria most of the people work full-time, so the variability in hours happens mostly along the extensive margin, i.e., employment, and not that much along the intensive margin, or hours per worker.

\footnotetext{
${ }^{3}$ Zanetti (2007) uses a similar mechanism to Maffezzoli (2001) but in a New-Keynesian framework. Zanetti (2007) and Faccini et al. (2013) are also examples of studies that investigate the effect of wage rigidities on business cycle fluctuations. However, his focus is also slightly different from ours. For alternative ways of modeling the labor market the reader is referred to Vasilev (2016, 2017a, b, c). Those setups are not totally incompatible with the union model presented here, but could be considered as a complementary to the union bargaining mechanism.

${ }^{4}$ Indeed, the two big unions in Bulgaria-KNSB and Podkrepa—cover both private- and public-sector employees. Extending the model along with this dimension will not significantly change the results in the paper.
} 
Overall, the calibrated model with collective bargaining mechanism between the union and the firm provides a tractable general-equilibrium setup, which performs well vis-a-vis data when it comes to relative volatilities of time series, auto- and crosscorrelation functions, and in addition dominates both the market-clearing labor market specification with indivisible labor as in Rogerson and Wright (1988). More specifically, the presence of the monopoly union causes labor productivity in the model to lead employment over the business cycle, which is what we observe in the data as well. The very low dynamic correlation between wages and employment in Bulgaria is wellapproximated in the model, mostly due to the fact that the wage rate is generated as an outcome of a sequential bargaining procedure. The model with unions also generates persistence in output and both employment and unemployment, and is able to respond to the criticism in Nelson and Plosser (1982), Cogley and Nason (1995), Rotemberg and Woodford (1996), and Hall (1999) who all argue that RBC models generally do not have a strong internal propagation mechanism (besides the strong persistence in the TFP process, that is).

The rest of the paper is organized as follows: Sect. 2 describes the model setup and characterizes the decentralized competitive equilibrium system, Sect. 3 discusses the calibration procedure, and Sect. 4 presents the steady-state model solution. Section 5 proceeds with the out-of-steady-state dynamics of all model variables, and compares the simulated second moments of theoretical variables against their empirical counterparts. Section 6 concludes the paper.

\section{Model description}

There is a continuum of homogeneous households, which derive utility out of consumption and leisure. The time available to households can be either spent in productive use or as leisure. The government taxes consumption spending, and levies a common proportional tax on all income, in order to finance non-productive purchases of government consumption goods, and government transfers. On the production side, there is a representative firm, which hires labor and capital to produce a homogeneous final good, which could be used for consumption, investment, or government purchases. The wage rate in the economy is determined by a utility-maximizing union, as in Maffezzoli (2001), subject to the firm's conditional labor demand.

\subsection{Households}

Each household $i, i \in[0,1]$, maximizes the following utility function, which, as in Rogerson and Wright (1988), is non-separable in consumption and leisure:

$$
\max _{\left\{c_{t}^{i}, h_{t}^{i}\right\}_{t=0}^{\infty}} E_{0} \sum_{t=0}^{\infty} \beta^{t} \frac{\left[c_{t}^{i}\left(1-h_{t}^{i}\right)^{\psi}\right]^{1-\mu}}{1-\mu},
$$

where $E_{0}$ is the expectation operation conditional on information available as of $t=0,0<\beta<1$ is the discount factor, $c_{t}^{i}$ is individual household consumption in 
period $t$, and $h_{t}^{i}$ are total hours worked. Parameter $\psi>0$ reflects the relative weight attached to the dis-utility of work, and $\mu>1$ captures the curvature of the utility function.

Each household $i$ faces a non-convex labor supply decision, $h_{t}^{i} \in\{0 ; \bar{h}\}, \forall t$, with $\bar{h}<1$. Hours supplied to the representative firm are rewarded at the hourly wage rate of $w_{t}$, so pre-tax labor income equals $w_{t} h_{t}$. In addition, each household starts with a positive endowment of physical capital, $k_{0}^{i}$, in period 0 , which is then rented to the firm at the rental rate $r_{t}$, so before-tax capital income equals $r_{t} k_{t}^{i}$. Households may also decide to invest in capital to augment the capital stock, which evolves according to the following law of motion:

$$
k_{t+1}^{i}=i_{t}^{i}+(1-\delta) k_{t}^{i},
$$

where $0<\delta<1$ is the depreciation rate of physical capital.

In addition to the rental income received, the household owns the firm, and thus has a legal claim to an equal share of the firm's profit, $\Pi_{t}=\pi_{t}$. The budget constraint faced by an individual household is then

$$
\left(1+\tau^{c}\right) c_{t}^{i}+k_{t+1}^{i}-(1-\delta) k_{t}^{i}=\left(1-\tau^{y}\right)\left[w_{t} h_{t}^{i}+r_{t} k_{t}^{i}+\pi_{t}\right]+g_{t}^{t},
$$

where $\tau^{c}$ is the tax rate on final consumption, $\tau^{y}$ is the proportional rate on labor and capital income, and $g_{t}^{t}$ are per household government transfers.

In equilibrium, following the argument in Hansen (1985) and Rogerson (1988), only a proportion $n_{t}, 0<n_{t}<1$ of all households will be employed in each period, ${ }^{5}$ which will denote the employment rate; note that the employment rate in the model is allowed to be time-varying. In addition, as in Rogerson and Wright (1988) and King and Rebelo (2000), we no longer have complete insurance, which will equalize consumption across employment states. In this model

$$
c_{t}^{e}=c_{t}^{u}(1-\bar{h})^{\frac{\psi}{\mu}-\psi},
$$

where $c_{t}^{e}$ and $c_{t}^{u}$ denote consumption levels of a worker and a non-worker, respectively, and where we have suppressed the $i$ notation. Note that for $0<\bar{h}<1, \mu>1$ and $\psi>0,(1-\bar{h})^{\frac{\psi}{\mu}-\psi}>1$. In other words, an employed individual would receive a higher consumption that that of an unemployed individual, $c_{t}^{e}>c_{t}^{u}$. As argued in Rogerson and Wright (1988), it can be also shown that the wage rate of an employed individual is higher than the marginal product of labor, hence the model will generate involuntary unemployment even in the absence of any other frictions in the labor market.

After aggregation over individual preferences, the aggregate household now features different preferences. It maximizes the following aggregate utility function

$$
\max _{\left\{c_{t}, n_{t}\right\}_{t=0}^{\infty}} E_{0} \sum_{t=0}^{\infty} \beta^{t} \frac{\left[c_{t} \phi\left(n_{t}\right)\right]^{1-\mu}}{1-\mu}
$$

\footnotetext{
5 Those who are ex-post employed will be chosen at random by the employer, as all workers are identical from the perspective of the firm).
} 
where we have suppressed the $u$ superscript for consumption, and

$$
\phi\left(n_{t}\right)=\left[n_{t}(1-\bar{h})^{\frac{\psi}{\mu}(1-\mu)}+\left(1-n_{t}\right)\right]^{\frac{1}{1-\mu}}
$$

As in Maffezzoli (2001), the function above will be interpreted as the disutility of employment for the aggregate household. The elasticity of $\phi($.$) with$ respect to employment is $\xi_{\phi}=\phi^{\prime}(n) n / \phi(n)$.

Next, since the aggregate household has effectively pooled together all capital resources, hence $k_{0}^{i}=k_{0}, \forall i$. This result amends the aggregate budget constraint as follows

$$
\left(1+\tau^{c}\right) c_{t}+k_{t+1}-(1-\delta) k_{t}=\left(1-\tau^{y}\right)\left[w_{t} n_{t} \bar{h}+r_{t} k_{t}+\pi_{t}\right]+g_{t}^{t} .
$$

As in Maffezzoli (2001), we will refer to this setup as the "Rogerson-Wright economy", or "RW", after Rogerson and Wright (1988). The Lagrangean of the aggregate household's problem is then

$$
\begin{aligned}
\mathcal{L}= & E_{0} \sum_{t=0}^{\infty} \beta^{t}\left\{\frac{\left[c_{t} \phi\left(n_{t}\right)\right]^{1-\mu}}{1-\mu}-\lambda_{t}\left[\left(1+\tau^{c}\right) c_{t}+k_{t+1}-(1-\delta) k_{t}\right.\right. \\
& \left.\left.-\left(1-\tau^{y}\right)\left[w_{t} n_{t} \bar{h}+r_{t} k_{t}+\pi_{t}\right]-g_{t}^{t}\right]\right\} .
\end{aligned}
$$

The first-order optimality conditions (FOCs) and the transversality condition are as follows:

$$
\begin{gathered}
c_{t}: \quad c_{t}^{-\mu}\left[\phi\left(n_{t}\right)\right]^{1-\mu}=\left(1+\tau^{c}\right) \lambda_{t} \\
n_{t}: \quad c_{t}^{1-\mu}\left[\phi\left(n_{t}\right)\right]^{-\mu}=\lambda_{t}\left(1-\tau^{y}\right) w_{t} \bar{h}, \\
k_{t+1}: \quad \lambda_{t}=\beta E_{t} \lambda_{t+1}\left[1-\delta+\left(1-\tau^{y}\right) r_{t+1}\right] \\
T V C_{k}: \quad \lim _{t \rightarrow \infty} \beta^{t} \lambda_{t} k_{t+1}=0,
\end{gathered}
$$

where $\lambda_{t}$ is the Lagrangean multiplier attached to the aggregate household's period- $t$ budget constraint. The interpretation of the optimality conditions is standard in the literature. In the first, the household equates the marginal utility of consumption, to the VAT-adjusted shadow price of wealth. The second equation determines the optimal employment, where the household balances the marginal cost to the marginal benefit from working. The remaining equations from the original FOCs are standard: for example, the Euler equation for capital stock describes how capital is allocated across any adjacent periods in order to maximize household's utility. The transversality conditions (TVCs) for physical capital is a boundary condition imposed to rule out explosive solutions in the model. 


\subsection{Firm's problem}

There is a representative firm in the economy, which produces a homogeneous final product. The price of output is normalized to unity. The production technology is Cobb-Douglas and uses both physical capital, $k_{t}$, and labor hours, $n_{t} \bar{h}$, to maximize static profit

$$
\Pi_{t}=A_{t} k_{t}^{\alpha}\left(n_{t} \bar{h}\right)^{1-\alpha}-r_{t} k_{t}-w_{t} h_{t},
$$

where $A_{t}$ denotes the level of technology in period $t, 0<\alpha, 1-\alpha<1$ denote the capital and labor share, respectively.

Since the firm rents the capital from households, the problem of the firm is a sequence of static profit maximizing problems. In equilibrium, there are no profits, and each input is priced according to its marginal product, i.e.:

$$
\begin{gathered}
k_{t}: \alpha \frac{y_{t}}{k_{t}}=r_{t}, \\
n_{t} \bar{h}: \quad(1-\alpha) \frac{y_{t}}{h_{t}}=w_{t} .
\end{gathered}
$$

In equilibrium, given that the inputs of production are paid their marginal products, $\pi_{t}=0, \forall t$.

\subsection{The monopoly union}

In an alternative setup, which we refer to as "the monopoly-union model", or "MU", the workers no longer choose their individual labor supply. In other words, the optimality condition for labor supply, Eq. (10), will be no longer a part of the equilibrium system. Instead, the condition determining optimal employment will be obtained from the union optimization problem described below. In other words, in the MU setup workers have decided that by organizing into a labor union, they can bargain more successfully as a group, and in turn, can extract some of the producer surplus. Here, we take the presence of unions as an empirical regularity, and do not focus on the process of union formation itself. For example, Westermark (1999) shows that substitutable workers have an incentive to organize into unions, while complementary workers do not. In our model, the assumption of homogeneous households is thus equivalent to having a unit mass of perfectly substitutable workers. Alternatively, with everyone in the union, the organization is able to achieve complete diversification, and thus its preferences are risk-neutral.

The unions can be now aggregated into a representative union bargaining with the representative firm: the union and the firm will then jointly determine the wage rate and the aggregate unemployment rate. In order to prevent union members who turn out to be unemployed ex post from leaving the union, the union has to provide a fair insurance against unemployment incidence. This is the approach followed in Maffezzoli (2001) and Benassy (1997), which we adopt in this paper, and which 
allows us to abstract away from heterogeneity driven by the employment status. As a result, the marginal utility of consumption is equalized across employed and unemployed individuals, and the aggregation into a single aggregate household is possible.

The union is now a single seller of labor services, and behaves as a monopolist in the that market. As in Oswald (1982) and Palokangas (2000), the union's objective is to maximize the members' expected wage bill, or:

$$
n_{t} w_{t}+\left(1-n_{t}\right) \bar{w}_{t}
$$

s.t. the firm's conditional labor demand

$$
w_{t}=(1-\alpha) \frac{y_{t}}{n_{t} \bar{h}},
$$

where $n_{t}$ is the employment rate, and $\bar{w}_{t}$ denotes the unions' reservation wage. The reservation wage can be viewed as the disutility of employment perceived by the unions, and inclusive of any type of unemployment benefits. As in Maffezzoli (2001), the sequence of reservation wages will be taken as being exogenous $\left\{\bar{w}_{t}\right\}_{t=0}^{\infty}$. The novelty in this paper is that in contrast to Maffezzoli (2001), in this setup the reservation wages is responding to the state of the economy, or equivalently, the level of total factor productivity. We believe this technical assumption to be a better description of reality, and in addition helps the model match data along the labor market dimension. ${ }^{6}$

Note that the union takes as given the conditional labor demand of the representative firm, as well as the reservation wage. In other words, once the wage rate is determined, firms choose the employment rate along the labor demand curve. This assumption is standard in this class of "monopoly union" setups, e.g. Dunlop (1944), Manning (1987) and Oswald (1982). Note that although a union is large at the firm or sector level, it is small at the aggregate level, and thus takes unions take $r_{t}$ as given.

The union and the firm then solve a sequence of independent games, due to the fact that (1) the monopoly union takes the rental rate of capital as given; (2) precommitment is ruled out, and (3) the services provided by the capital and labor inputs are purchased in each period $t$. Therefore, in the absence of credible pre-commitment, the union will not internalize the dynamic effect of today's wage on future investment, or the process of capital accumulation. In other words, investment in capital in equilibrium will be inefficiently low, and the wage rate is above its marginal product.

As in Maffezzoli (2001), and Anderson and Devereux (1988), we solve for the Markov equilibria, and more specifically, the focus is on Markov strategies depending only on current exogenous and endogenous state (predetermined) variables. The wage rate and the demand for capital will be jointly determined to form the Nash equilibrium of the game: the first two from the firm problem, while the employment will be determined from the union's maximization problem.

\footnotetext{
${ }^{6}$ Note that the union also takes $\left\{k_{t}\right\}_{t=0}^{\infty}$ as given.
} 
Substituting the expression for the wage from the firm's optimality condition, the union's objective function can be rewritten as

$$
n_{t} A_{t} k_{t}^{\alpha}\left(n_{t} \bar{h}\right)^{1-\alpha}+\left(1-n_{t}\right) \bar{w}_{t} .
$$

Maximizing then with respect to $n_{t}$ results in

$$
n_{t}=(1-\alpha)^{2} \frac{y_{t}}{\bar{w}_{t} \bar{h}},
$$

or the employment rate chosen by the monopoly union is proportional to output and the reservation wage, where the latter follows the path of total factor productivity. As in the monopoly in the product market, here marginal revenue is also less than the price (wage), so the employment rate chosen by the monopoly union and the firm is lower than the socially efficient level, hence there is involuntary unemployment. The corresponding union wage rate is then obtained from the firm's conditional labor demand function. Note that this differs from wage rigidity schemes used in other papers. In addition, the aggregate wage function is positively-sloped, but its slope bears no relationship to the elasticity of the individual labor supply. The searchtheoretic framework discussed in Hall and Liebman (1998), and Vasilev (2016) for the case of Bulgaria, features the same property - an elastic aggregate wage-setting function, which is compatible with inelastic labor supply at the individual household level. ${ }^{7}$ Therefore, the approach in this paper is also compatible with a search-theoretic model of the labor market. ${ }^{8}$

\subsection{Government}

In the model setup, the government is levying taxes on labor and capital income, as well as on consumption spending, in order to finance its spending on non-productive government purchases, and public transfers. The government budget constraint is as follows:

$$
g_{t}^{c}+g_{t}^{t}=\tau^{c} c_{t}+\tau^{y}\left[w_{t} \bar{h} n_{t}+r_{t} k_{t}\right]
$$

Income tax rate, consumption tax rate and government consumption-to-output ratio would be chosen to match the average share in data, while government transfers would be determined residually in each period so that the government budget is always balanced.

\subsection{Dynamic competitive equilibrium (DCE)}

For a given process followed by technology $\left\{A_{t}\right\}_{t=0}^{\infty}$, tax rates $\left\{\tau^{c}, \tau^{y}\right\}$, the fixed length of the work week $\bar{h}$, and initial capital stock $\left\{k_{0}\right\}$, the decentralized dynamic

\footnotetext{
7 The same property was documented for the RW economy.

8 The wage process, resulting from Nash bargaining in a search-theoretic model, is not a good descriptor of the observed wage dynamics in Bulgaria, though.
} 
Table 1 Model parameters

\begin{tabular}{llll}
\hline Parameters & Value & Description & Method \\
\hline$\beta$ & 0.982 & Discount factor & Calibrated \\
$\alpha$ & 0.429 & Capital share, production function & Data average \\
$\mu$ & 2.000 & Curvature parameter, utility function & Set \\
$\psi$ & 2.000 & Relative weight attached to leisure & Calibrated \\
$\delta$ & 0.013 & Depreciation rate on physical capital & Data average \\
$n$ & 0.533 & Employment rate & Data average \\
$\tau^{y}$ & 0.100 & Average tax rate on income & Data average \\
$\tau^{c}$ & 0.200 & VAT/consumption tax rate & Data average \\
$\rho_{a}$ & 0.701 & AR(1) persistence coefficient, TFP process & Estimated \\
$\sigma_{a}$ & 0.044 & St. error, TFP process & Estimated \\
\hline
\end{tabular}

competitive equilibrium is a list of sequences $\left\{c_{t}, i_{t}, k_{t}, n_{t}\right\}_{t=0}^{\infty}$ for the household, a sequence of government purchases and transfers $\left\{g_{t}^{c}, g_{t}^{t}\right\}_{t=0}^{\infty}$, and input prices $\left\{w_{t}, r_{t}\right\}_{t=0}^{\infty}$ such that (1) the household maximizes its utility function subject to its budget constraint; (2) the representative firm maximizes profit; (3) in the union model, the union maximizes its objective function subject to the conditional demand for labor; (4) government budget is balanced in each period; (5) all markets clear.

\section{Data and model calibration}

To characterize business cycle fluctuations in Bulgaria, we will focus on the period following the introduction of the currency board (1999-2018). Quarterly data on output, consumption and investment was collected from Bulgarian National Bank (2019), while the real interest rate is taken from Bulgarian National Bank Statistical Database (2019). The calibration strategy described in this section follows a long-established tradition in modern macroeconomics: first, as in Vasilev (2016), the discount factor, $\beta=0.982$, is set to match the steady-state capital-to-output ratio in Bulgaria, $k / y=13.964$, in the steady-state Euler equation. The capital share, $\alpha=0.429$, was estimated as in Vasilev (2017d). Next, the average income tax rate was set to $\tau^{y}=0.1$. This is the average effective tax rate on income between 1999 and 2007, when Bulgaria used progressive income taxation, and equal to the proportional income tax rate introduced as of 2008. Similarly, the average tax rate on consumption is set to its value over the period, $\tau^{c}=0.2$.

The value of the curvature parameter of the utility function is set to $\mu=2$, which is a standard value in the literature. The relative weight attached to the utility out of leisure in the household's utility function, $\psi=2$, is calibrated to match that in steady-state consumers would supply one-third of their time endowment to working. This is in line with the estimates for Bulgaria (Vasilev 2017a) as well over the period studied. This calibration produces a value of the elasticity of the disutility of unemployment, $\xi_{\phi}=0.757$. Employment rate, $n=0.533$, was also set to its average value over the period studied. 
Table 2 Data averages and long-run solution

\begin{tabular}{llcc}
\hline Variable & Description & Data & $\begin{array}{c}\text { Model } \\
\text { (RW \& } \\
\text { MU) }\end{array}$ \\
\hline$y$ & & & 1.000 \\
$c / y$ & Steady-state output & N/A & 0.674 \\
$i / y$ & Consumption-to-output ratio & 0.648 & 0.175 \\
$k / y$ & Investment-to-output ratio & 0.201 & 13.96 \\
$g^{c} / y$ & Capital-to-output ratio & 13.96 & 0.151 \\
$w n \bar{h} / y$ & Government consumption-to-output ratio & 0.151 & 0.571 \\
$r k / y$ & Labor income-to-output ratio & 0.571 & 0.429 \\
$\bar{h}$ & Capital income-to-output ratio & 0.429 & 0.333 \\
$\bar{r}$ & Share of time spent working & 0.333 & 0.016 \\
\hline
\end{tabular}

Next, the average depreciation rate of physical capital in Bulgaria, $\delta=0.013$, was taken from Vasilev (2016). It was estimated as the average quarterly depreciation rate over the period 1999-2014. Finally, the TFP process is estimated from the detrended series by running an $\mathrm{AR}(1)$ regression and saving the residuals. Table 1 below summarizes the values of all model parameters used in the paper.

\section{Steady-state}

Once the values of model parameters were obtained, the steady-state equilibrium system solved, the "big ratios" can be compared to their averages in Bulgarian data. Both models produce the same steady-state; the results are reported in Table 2 below. The steady-state level of output was normalized to unity (hence the level of technology $A$ differs from one, which is usually the normalization done in other studies), which greatly simplified the computations. Next, the models match government purchases ratios by construction; the consumption-to-output and investment ratio is also relatively closely approximated, despite the closed-economy assumption and the absence of foreign trade sector. The shares of income are also identical to those in data, which is an artefact of the assumptions imposed on functional form of the aggregate production function. The after-tax return, where $\bar{r}=\left(1-\tau^{y}\right) r-\delta$ is also relatively well-captured by the model. Lastly, given the absence of debt, and the fact that public transfers were chosen residually to balance the government budget constraint, the result along this dimension is understandably not so close to the average ratio in data.

\section{Out of steady-state model dynamics}

Since both models do not have an analytical solution for the equilibrium behavior of variables outside their steady-state values, we need to solve the models numerically. This is done by log-linearizing the original equilibrium (non-linear) system of 

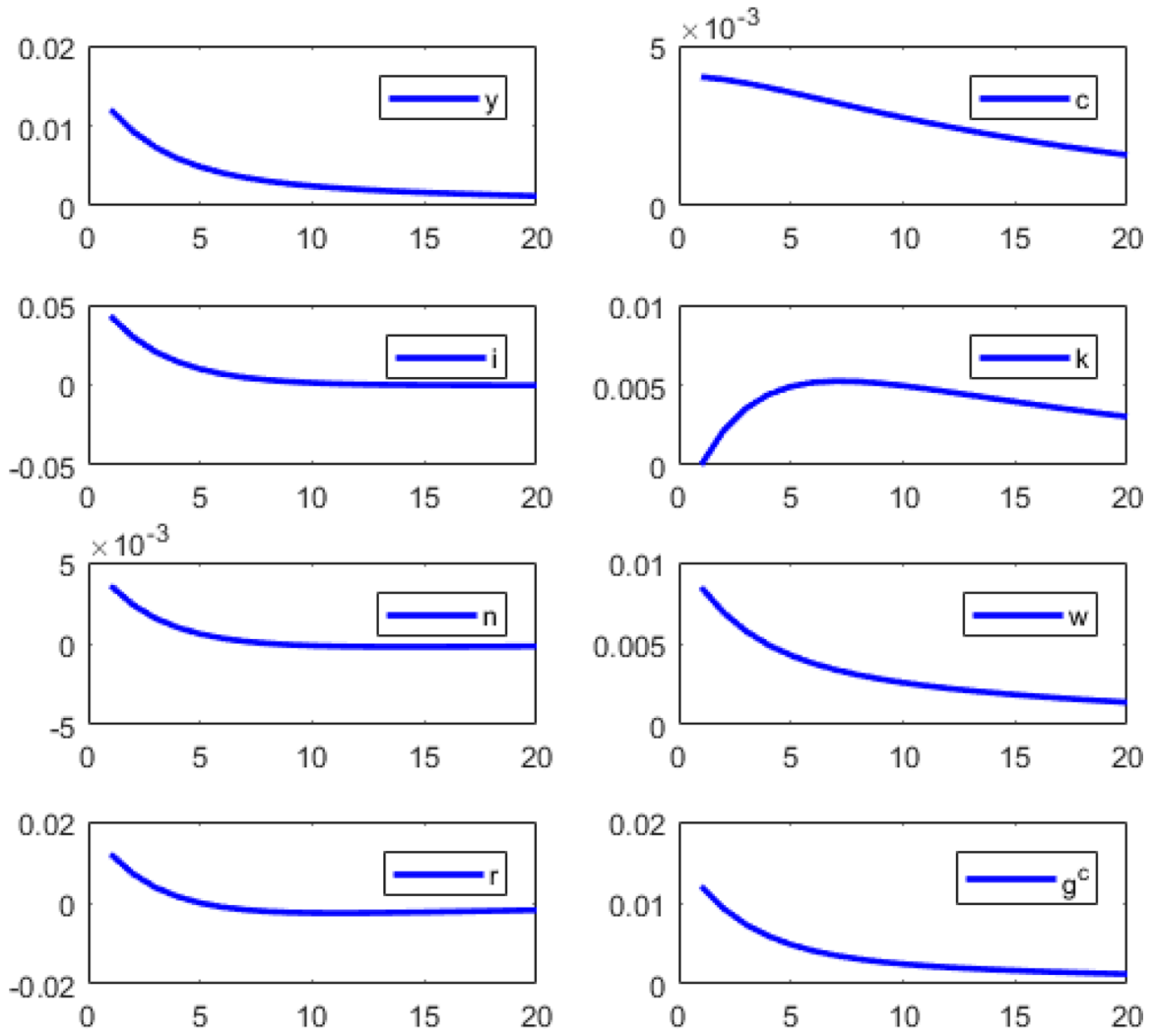

Fig. 2 Impulse responses to a 1\% surprise innovation in technology, RW model

equations around the steady-state. This transformation produces a first-order system of stochastic difference equations. First, we study the dynamic behavior of model variables to an isolated shock to the total factor productivity process, and then we fully simulate the model to compare how the second moments of the model perform when compared against their empirical counterparts.

\subsection{Impulse response analysis}

This subsection documents the impulse responses of model variables to a $1 \%$ surprise innovation to technology. The impulse response functions (IRFs) are presented in Figs. 2 and 3 and on the next page. For expositional purposes, the two models (RW and MU) are presented separately. As a result of the one-time unexpected positive shock to total factor productivity, output increases upon impact. This expands the availability of resources in the economy, so used of output-consumption, investment, and government consumption also increase contemporaneously.

At the same time, the increase in productivity increases the after-tax return on the two factors of production, labor and capital. The representative households then 

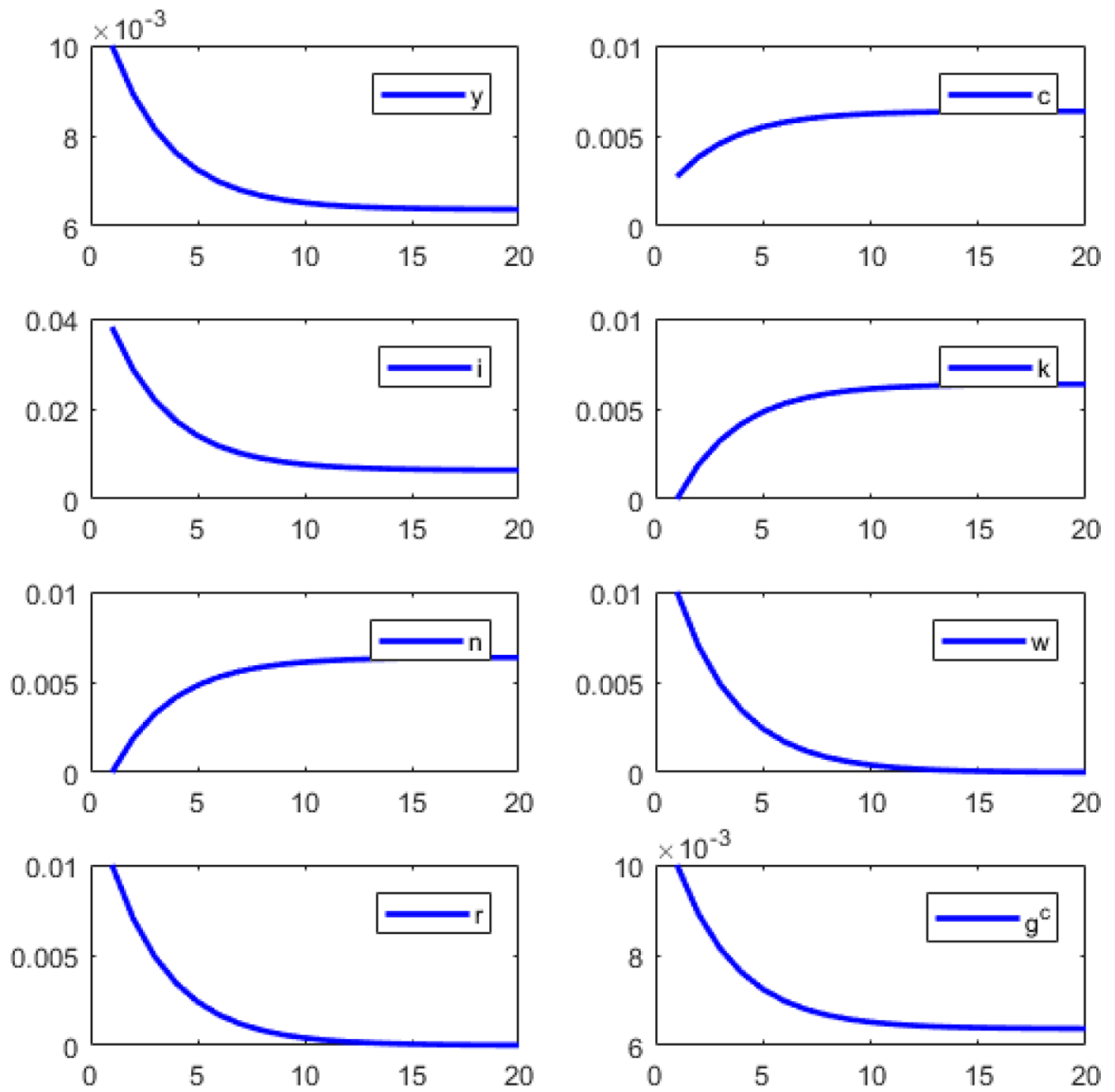

Fig. 3 Impulse responses to a 1\% surprise innovation in technology, MU model

respond to the incentives contained in prices and start accumulating capital, and supplies more hours worked. In turn, the increase in capital input feeds back in output through the production function and that further adds to the positive effect of the technology shock. In the labor market, the wage rate increases, and the household increases its hours worked. In turn, the increase in total hours further increases output, again indirectly.

Over time, as capital is being accumulated, its after-tax marginal product starts to decrease, which lowers the households' incentives to save. As a result, physical capital stock eventually returns to its steady-state, and exhibits a hump-shaped dynamics over its transition path. The rest of the model variables return to their old steady-states in a monotone fashion as the effect of the one-time surprise innovation in technology dies out.

In the case of the union model, the effect of the technology shock is short-lived due to the fact that the union does not internalize the capital externality. In other words, the sequential bargaining between the union and the firm now is a major 
Table 3 Business cycle moments

\begin{tabular}{lcll}
\hline & Data & Model RW & MU model \\
\hline$\sigma_{y}$ & 0.05 & 0.05 & 0.05 \\
$\sigma_{c} / \sigma_{y}$ & 0.55 & 0.76 & 0.95 \\
$\sigma_{i} / \sigma_{y}$ & 1.77 & 2.34 & 1.56 \\
$\sigma_{g} / \sigma_{y}$ & 1.21 & 1.00 & 1.00 \\
$\sigma_{n} / \sigma_{y}$ & 0.63 & 0.17 & 0.95 \\
$\sigma_{w} / \sigma_{y}$ & 0.83 & 0.88 & 0.33 \\
$\sigma_{y / h} / \sigma_{y}$ & 0.86 & 0.88 & 0.33 \\
$\operatorname{corr}(c, y)$ & 0.85 & 0.92 & 0.95 \\
$\operatorname{corr}(i, y)$ & 0.61 & 0.89 & 0.79 \\
$\operatorname{corr}(g, y)$ & 0.31 & 1.00 & 1.00 \\
$\operatorname{corr}(n, y)$ & 0.49 & 0.72 & 0.91 \\
$\operatorname{corr}(w, y)$ & -0.01 & 0.99 & 0.31 \\
\hline
\end{tabular}

internal mechanism, which quantitatively dominates the work of the capital accumulation. Note that with unions there is no intra-temporal optimality between consumption and labor, as the household no longer individually determines its labor supply. The two models also produce different dynamics for the wage rate, in the RW economy, it follows a hump shape, while in the union model, it converges monotonically.

\subsection{Simulation and moment-matching}

As in Vasilev (2017b), we will now simulate the model 10,000 times for the length of the data horizon. Both empirical and model simulated data is detrended using the Hodrick and Prescott (1980) filter. Table 3 on the next page summarizes the second moments of data (relative volatilities to output, and contemporaneous correlations with output) versus the same moments computed from the model-simulated data at quarterly frequency. To minimize the sample error, the simulated moments are averaged out over the computer-generated draws. As in Vasilev (2016, 2017b, c), both models match quite well the absolute volatility of output; by construction, government consumption in the model varies as much as output. In addition, the predicted consumption volatilities are a bit too high, where the increase in consumption variability in the union could be attributed to the collective bargaining mechanism. Still, the model is qualitatively consistent with the stylized fact that consumption generally varies less than output, while investment is more volatile than output. Again, the union model is closer to data in terms of the magnitude of the empirical investment volatility. With a monopoly union in the model, the quantitative importance of capital accumulation is now lower, and as a result, investment variability is depressed.

With respect to the labor market variables, the variability of employment predicted by the model is lower than that in data in the RW setup, and higher in the MU model. On the other hand, the variability of wages in the model is very close to that in data for the RW economy, and a bit too low in the MU model. This is yet another confirmation that the perfectly-competitive assumption, that wages equal 
their marginal product, used also in Vasilev (2009), as well as the benchmark calibration of the RW model with indivisible labor here, does not describe very well the dynamics of labor market variables, even when we allow for the presence of unions.

Next, in terms of contemporaneous correlations, both models systematically overpredicts the pro-cyclicality of the main aggregate variables-consumption, investment, government consumption, and employment. This, however, is a common limitation of this class of RBC models. With respect to wages, the RW setup predicts a strong pro-cyclicality, while wages in data are a-cyclical. This shortcoming is wellknown in the literature and an artefact of the wage being equal to the labor productivity in the model. In contrast, the monopoly union model provides a better description of the labor market dynamics in Bulgaria, as it only predicts a moderate wage pro-cyclicality. In addition, the correlation of wages and output drops to zero if the reservation wage does not respond to productivity shocks. ${ }^{9}$ This is a success for the MU model, since, after all, not all of the Bulgarian economy is unionized, and most of the collective bargaining procedures takes place at a firm's level.

In the next subsection, as in Vasilev (2015c), we investigate the dynamic correlation between labor market variables at different leads and lags, thus evaluating how well the model matches the phase dynamics among variables. In addition, the autocorrelation functions (ACFs) of empirical data, obtained from an unrestricted VAR(1) are put under scrutiny and compared and contrasted to the simulated counterparts generated from the two competing models.

\subsection{Auto- and cross-correlation}

This subsection discusses the auto-(ACFs) and cross-correlation functions (CCFs) of the major model variables. The coefficients empirical ACFs and CCFs at different leads and lags are presented in Tables 4 and 5 below against the averaged simulated AFCs and CCFs. Following Canova (2007), this exercise is used as a goodness-of-fit measure.

Both models compare relatively well vis-a-vis data. Empirical ACFs for output and investment are slightly outside the confidence band predicted by the model, while the ACFs for total factor productivity and household consumption are wellapproximated by the model. The persistence of labor market variables is also relatively well-described by the model dynamics. Overall, both models generate too much persistence in output and both employment and unemployment, and is subject to the criticism in Nelson and Plosser (1982), Cogley and Nason (1995), Rotemberg and Woodford (1996), and Hall (1999), who argue that the RBC class of models do not have a strong internal propagation mechanism besides the strong persistence in the TFP process. In those models, e.g. the RW setup, labor market is modeled in the Walrasian market-clearing spirit, and output and unemployment persistence is low. Indeed, when unions are allowed in the model, the MU setup is marginally better than the RW in terms of autocorrelations.

\footnotetext{
9 Maffezzoli (2001) does not report the volatility of wages in his calibration for Italy, but from the impulse responses it can be seen that his model suffers from very low wage variability as well.
} 
Table 4 Autocorrelations for Bulgarian data and the RW model economy

\begin{tabular}{|c|c|c|c|c|c|}
\hline \multirow[t]{2}{*}{ Methods } & \multirow[t]{2}{*}{ Statistic } & \multicolumn{4}{|l|}{$\mathrm{k}$} \\
\hline & & 0 & 1 & 2 & 3 \\
\hline Data & $\operatorname{corr}\left(u_{t}, u_{t-k}\right)$ & 1.000 & 0.765 & 0.552 & 0.553 \\
\hline Model RW & $\begin{array}{l}\operatorname{corr}\left(u_{t}, u_{t-k}\right) \\
(\mathrm{SE})\end{array}$ & $\begin{array}{l}1.000 \\
(0.000)\end{array}$ & $\begin{array}{l}0.954 \\
(0.028)\end{array}$ & $\begin{array}{l}0.897 \\
(0.054)\end{array}$ & $\begin{array}{l}0.831 \\
(0.071)\end{array}$ \\
\hline Data & $\operatorname{corr}\left(n_{t}, n_{t-k}\right)$ & 1.000 & 0.484 & 0.009 & 0.352 \\
\hline Model RW & $\begin{array}{l}\operatorname{corr}\left(n_{t}, n_{t-k}\right) \\
(\mathrm{SE})\end{array}$ & $\begin{array}{l}1.000 \\
(0.000)\end{array}$ & $\begin{array}{l}0.954 \\
(0.028)\end{array}$ & $\begin{array}{l}0.897 \\
(0.054)\end{array}$ & $\begin{array}{l}0.831 \\
(0.071)\end{array}$ \\
\hline Data & $\operatorname{corr}\left(y_{t}, y_{t-k}\right)$ & 1.000 & 0.810 & 0.663 & 0.479 \\
\hline Model RW & $\begin{array}{l}\operatorname{corr}\left(y_{t}, y_{t-k}\right) \\
(\mathrm{SE})\end{array}$ & $\begin{array}{l}1.000 \\
(0.000)\end{array}$ & $\begin{array}{l}0.957 \\
(0.026)\end{array}$ & $\begin{array}{l}0.906 \\
(0.050)\end{array}$ & $\begin{array}{l}0.848 \\
(0.072)\end{array}$ \\
\hline Data & $\operatorname{corr}\left(a_{t}, a_{t-k}\right)$ & 1.000 & 0.702 & 0.449 & 0.277 \\
\hline Model RW & $\begin{array}{l}\operatorname{corr}\left(a_{t}, a_{t-k}\right) \\
(\mathrm{SE})\end{array}$ & $\begin{array}{l}1.000 \\
(0.000)\end{array}$ & $\begin{array}{l}0.954 \\
(0.028)\end{array}$ & $\begin{array}{l}0.900 \\
(0.053)\end{array}$ & $\begin{array}{l}0.837 \\
(0.077)\end{array}$ \\
\hline Data & $\operatorname{corr}\left(c_{t}, c_{t-k}\right)$ & 1.000 & 0.971 & 0.952 & 0.913 \\
\hline Model RW & $\begin{array}{l}\operatorname{corr}\left(c_{t}, c_{t-k}\right) \\
(\mathrm{SE})\end{array}$ & $\begin{array}{l}1.000 \\
(0.000)\end{array}$ & $\begin{array}{l}0.958 \\
(0.024)\end{array}$ & $\begin{array}{l}0.909 \\
(0.047)\end{array}$ & $\begin{array}{l}0.855 \\
(0.069)\end{array}$ \\
\hline Data & $\operatorname{corr}\left(i_{t}, i_{t-k}\right)$ & 1.000 & 0.810 & 0.722 & 0.594 \\
\hline Model RW & $\begin{array}{l}\operatorname{corr}\left(i_{t}, i_{t-k}\right) \\
(\mathrm{SE})\end{array}$ & $\begin{array}{l}1.000 \\
(0.000)\end{array}$ & $\begin{array}{l}0.955 \\
(0.028)\end{array}$ & $\begin{array}{l}0.900 \\
(0.053)\end{array}$ & $\begin{array}{l}0.836 \\
(0.077)\end{array}$ \\
\hline Data & $\operatorname{corr}\left(w_{t}, w_{t-k}\right)$ & 1.000 & 0.760 & 0.783 & 0.554 \\
\hline Model RW & $\begin{array}{l}\operatorname{corr}\left(w_{t}, w_{t-k}\right) \\
(\mathrm{SE})\end{array}$ & $\begin{array}{l}1.000 \\
(0.000)\end{array}$ & $\begin{array}{l}0.957 \\
(0.025)\end{array}$ & $\begin{array}{l}0.907 \\
(0.049)\end{array}$ & $\begin{array}{l}0.851 \\
(0.071)\end{array}$ \\
\hline
\end{tabular}

A similar picture can be observed in the cross-correlations: as seen from Table 6 below, over the business cycle, in data labor productivity leads employment. The RW model, however, cannot account for this fact. As in the standard RBC model, a technology shock can be regarded as a factor shifting the labor demand curve, while holding the labor supply curve constant. Therefore, the effect between employment and labor productivity is only a contemporaneous one.

In contrast, the model with a monopoly union, where the wage is determined via a sequential bargaining procedure between the firm and the union, is able to match the low contemporaneous correlation between hours and wages, as well as the general dynamic pattern at various leads and lags (see Table 7). This is yet another indication that the presence of unions and collective agreements is important for the observed dynamics in the labor market in Bulgaria for the period after the introduction of the currency board.

\section{Conclusions}

In this paper, we investigate the quantitative importance of collective bargaining agreements for the observed fluctuations in Bulgarian labor markets. Following Maffezzoli (2001), we introduce a monopoly union into a real-business-cycle 
Table 5 Autocorrelations for Bulgarian data and the MU model economy

\begin{tabular}{|c|c|c|c|c|c|}
\hline \multirow[t]{2}{*}{ Method } & \multirow[t]{2}{*}{ Statistic } & \multicolumn{3}{|l|}{$\mathrm{k}$} & \multirow[b]{2}{*}{3} \\
\hline & & 0 & 1 & 2 & \\
\hline Data & $\operatorname{corr}\left(u_{t}, u_{t-k}\right)$ & 1.000 & 0.765 & 0.552 & 0.553 \\
\hline Model MU & $\begin{array}{l}\operatorname{corr}\left(u_{t}, u_{t-k}\right) \\
(\mathrm{SE})\end{array}$ & $\begin{array}{l}1.000 \\
(0.000)\end{array}$ & $\begin{array}{l}0.954 \\
(0.021)\end{array}$ & $\begin{array}{l}0.905 \\
(0.041)\end{array}$ & $\begin{array}{l}0.852 \\
(0.060)\end{array}$ \\
\hline Data & $\operatorname{corr}\left(n_{t}, n_{t-k}\right)$ & 1.000 & 0.484 & 0.009 & 0.352 \\
\hline Model MU & $\begin{array}{l}\operatorname{corr}\left(n_{t}, n_{t-k}\right) \\
(\mathrm{SE})\end{array}$ & $\begin{array}{l}1.000 \\
(0.000)\end{array}$ & $\begin{array}{l}0.954 \\
(0.021)\end{array}$ & $\begin{array}{l}0.905 \\
(0.041)\end{array}$ & $\begin{array}{l}0.852 \\
(0.060)\end{array}$ \\
\hline Data & $\operatorname{corr}\left(y_{t}, y_{t-k}\right)$ & 1.000 & 0.810 & 0.663 & 0.479 \\
\hline Model MU & $\begin{array}{l}\operatorname{corr}\left(y_{t}, y_{t-k}\right) \\
(\mathrm{SE})\end{array}$ & $\begin{array}{l}1.000 \\
(0.000)\end{array}$ & $\begin{array}{l}0.954 \\
(0.023)\end{array}$ & $\begin{array}{l}0.903 \\
(0.045)\end{array}$ & $\begin{array}{l}0.849 \\
(0.065)\end{array}$ \\
\hline Data & $\operatorname{corr}\left(a_{t}, a_{t-k}\right)$ & 1.000 & 0.702 & 0.449 & 0.277 \\
\hline Model MU & $\begin{array}{l}\operatorname{corr}\left(a_{t}, a_{t-k}\right) \\
(\mathrm{SE})\end{array}$ & $\begin{array}{l}1.000 \\
(0.000)\end{array}$ & $\begin{array}{l}0.955 \\
(0.027)\end{array}$ & $\begin{array}{l}0.901 \\
(0.053)\end{array}$ & $\begin{array}{l}0.838 \\
(0.077)\end{array}$ \\
\hline Data & $\operatorname{corr}\left(c_{t}, c_{t-k}\right)$ & 1.000 & 0.971 & 0.952 & 0.913 \\
\hline Model MU & $\begin{array}{l}\operatorname{corr}\left(c_{t}, c_{t-k}\right) \\
(\mathrm{SE})\end{array}$ & $\begin{array}{l}1.000 \\
(0.000)\end{array}$ & $\begin{array}{l}0.954 \\
(0.021)\end{array}$ & $\begin{array}{l}0.905 \\
(0.042)\end{array}$ & $\begin{array}{l}0.851 \\
(0.061)\end{array}$ \\
\hline Data & $\operatorname{corr}\left(i_{t}, i_{t-k}\right)$ & 1.000 & 0.810 & 0.722 & 0.594 \\
\hline Model MU & $\begin{array}{l}\operatorname{corr}\left(i_{t}, i_{t-k}\right) \\
(\mathrm{SE})\end{array}$ & $\begin{array}{l}1.000 \\
(0.000)\end{array}$ & $\begin{array}{l}0.954 \\
(0.026)\end{array}$ & $\begin{array}{l}0.901 \\
(0.051)\end{array}$ & $\begin{array}{l}0.841 \\
(0.074)\end{array}$ \\
\hline Data & $\operatorname{corr}\left(w_{t}, w_{t-k}\right)$ & 1.000 & 0.760 & 0.783 & 0.554 \\
\hline Model MU & $\begin{array}{l}\operatorname{corr}\left(w_{t}, w_{t-k}\right) \\
(\mathrm{SE})\end{array}$ & $\begin{array}{l}1.000 \\
(0.000)\end{array}$ & $\begin{array}{l}0.955 \\
(0.027)\end{array}$ & $\begin{array}{l}0.901 \\
(0.053)\end{array}$ & $\begin{array}{l}0.838 \\
(0.077)\end{array}$ \\
\hline
\end{tabular}

Table 6 Dynamic correlations for Bulgarian data and the RW model economy

\begin{tabular}{llllllllll}
\hline Method & Statistic & $\mathrm{k}$ & & & & & \\
& & & -3 & -2 & -1 & 0 & 1 & 2 & 3 \\
\hline Data & $\operatorname{corr}\left(n_{t},(y / n)_{t-k}\right)$ & -0.342 & -0.363 & -0.187 & -0.144 & 0.475 & 0.470 & 0.346 \\
RW & $\operatorname{corr}\left(n_{t},(y / n)_{t-k}\right)$ & 0.023 & 0.023 & 0.024 & 0.621 & 0.065 & 0.029 & 0.004 \\
& $(\mathrm{SE})$ & $(0.336)$ & $(0.292)$ & $(0.239)$ & $(0.224)$ & $(0.215)$ & $(0.259)$ & $(0.030)$ \\
Data & $\operatorname{corr}\left(n_{t}, w_{t-k}\right)$ & 0.355 & 0.452 & 0.447 & 0.328 & -0.040 & -0.390 & -0.57 \\
RW & $\operatorname{corr}\left(n_{t}, w_{t-k}\right)$ & 0.023 & 0.023 & 0.024 & 0.621 & 0.065 & 0.029 & 0.004 \\
& $(\mathrm{SE})$ & $(0.336)$ & $(0.292)$ & $(0.239)$ & $(0.224)$ & $(0.215)$ & $(0.259)$ & $(0.030)$ \\
\hline
\end{tabular}

model with government sector. We calibrate the model to Bulgarian data for the period following the introduction of the currency board arrangement (1999-2018), and compare and contrast it to a model without unions. We find that the sequential bargaining procedure between the monopoly union and the stand-in firm produces an important internal propagation mechanism within the theoretical setup, which 
Table 7 Dynamic correlations for Bulgarian data and the MU model economy

\begin{tabular}{llllllllll}
\hline Method & Statistic & $\mathrm{k}$ & & & & & & \\
\cline { 3 - 7 } & & -3 & -2 & -1 & 0 & 1 & 2 & 3 \\
\hline Data & $\operatorname{corr}\left(n_{t},(y / n)_{t-k}\right)$ & -0.342 & -0.363 & -0.187 & -0.144 & 0.475 & 0.470 & 0.346 \\
MU & $\operatorname{corr}\left(n_{t},(y / n)_{t-k}\right)$ & -0.045 & -0.043 & -0.036 & -0.030 & 0.028 & 0.038 & 0.043 \\
& $(\mathrm{SE})$ & $(0.326)$ & $(0.289)$ & $(0.250)$ & $(0.453)$ & $(0.280)$ & $(0.339)$ & $(0.388)$ \\
Data & $\operatorname{corr}\left(n_{t}, w_{t-k}\right)$ & 0.355 & 0.452 & 0.447 & 0.328 & -0.040 & -0.390 & -0.57 \\
MU & $\operatorname{corr}\left(n_{t}, w_{t-k}\right)$ & -0.045 & -0.043 & -0.036 & -0.030 & 0.028 & 0.038 & 0.043 \\
& $(\mathrm{SE})$ & $(0.326)$ & $(0.289)$ & $(0.250)$ & $(0.453)$ & $(0.280)$ & $(0.339)$ & $(0.388)$ \\
\hline
\end{tabular}

allows the monopoly model to fit data much better than the alternative framework with perfectly-competitive labor markets.

\section{Compliance with ethical standards}

Conflict of interest On behalf of all authors, Aleksandar Vasilev states that there is no conflict of interest.

Open Access This article is distributed under the terms of the Creative Commons Attribution 4.0 International License (http://creativecommons.org/licenses/by/4.0/), which permits unrestricted use, distribution, and reproduction in any medium, provided you give appropriate credit to the original author(s) and the source, provide a link to the Creative Commons license, and indicate if changes were made.

\section{References}

Anderson, S., \& Devereux, M. (1988). Trade unions and the choice of capital stock. Scandinavian Journal of Economics, 90, 27-44.

Benassy, J.-P. (1997). Imperfect competition, capital shortages and unemployment persitence. Scandinavian Journal of Economics, 99, 15-27.

Blanchard, O., \& Fischer, S. (1989). Lectures on macroeconomics. Cambridge: MIT Press.

Bulgarian National Bank. (2019). Bulgarian National Bank Statistics. http://www.bnb.bg. Accessed 21 Jul 2019.

Canova, F. (2007). Methods for applied macroeconomic research. Princeton: Princeton University Press.

Cogley, T., \& Nason, J. (1995). Output dynamics in real-business-cycles. American Economic Review, 85(3), 492-511.

Dunlop, J. (1944). Wage determination under trade unions. New York: Macmillan.

European Trade Union Institute. (2018). Industrial relations in Bulgaria. https://www.etui.org/Refor msWatch/Bulgaria. Accessed 15 Dec 2018.

Faccini, R., Millard, S., \& Zanetti, F. (2013). Wage rigidities in an estimated dynamic, stochastic, general equilibrium model of the UK labour market. The Manchester School, 81(S1), 66-99.

Farber, H. (1986). The analysis of union behaviour. In O. Ashenfelter \& R. Layard (Eds.), Handbook of labor economics (Vol. II). Amsterdam: New Holland.

Hall, R. (1999). Labor-market frictions and employment fluctuations. In M. Woodford \& J. Taylor (Eds.), Handbook of macroeconomics (Vol. IB). New York: Elsevier.

Hall, B. J., \& Liebman, J. B. (1998). Are CEOs really paid like bureaucrats? The Quarterly Journal of Economics, 113(3), 653-691.

Hansen, G. (1985). Indivisible labor and the business cycle. Journal of Monetary Economics, 16, 309-28. 
Hodrick, R., \& Prescott, E. (1980). Post-war US business cycles: An empirical investigation. Unpublished manuscript (Carnegie-Mellon University, Pittsburgh, PA).

King, R., \& Rebelo, S. (2000). Resuscitating real business cycles. In M. Woodford \& J. Taylor (Eds.), Handbook of macroeconomics (Vol. IB). New York: Elsevier.

Kydland, F., \& Prescott, E. (1982). Time to build and aggregate fluctuations. Econometrica, 50(6), $1345-70$.

Long, J., \& Plosser, C. (1983). Real business cycles. Journal of Political Economy, 91(1), 39-69.

Lozev, I., Vladova, Z., \& Paskaleva, D. (2011). Wage-setting behaviour of Bulgarian firms: Evidence from survey data, Discussion Paper 87. Sofia, Bulgaria: Bulgarian National Bank.

Maffezzoli, M. (2001). Non-Walrasian labor markets and real business cycles. Review of Economic Dynamics, 4, 860-892.

Manning, A. (1987). An integration of trade union models in a sequential bargaining framework. Economic Journal, 97, 121-139.

National Statistical Institute. (2019). Aggregate statistical indicators. http://www.nsi.bg. Accessed 21 Jul 2019.

Nelson, C. R., \& Plosser, C. I. (1982). Trends and random walks in macroeconmic time series: Some evidence and implications. Journal of Monetary Economics, 10(2), 139-162.

Oswald, A. (1982). The microeconomic theory of the trade union. Economic Journal, 92, 269-283.

Palokangas, T. (2000). Labour unions, public policy and economic growth. Cambridge: Cambridge University Press.

Paskaleva, D. (2016). Labour cost and price adjustment practices of Bulgarian firms in the period 2009_ 13, Discussion Paper 101. Sofia, Bulgaria: Bulgarian National Bank.

Rogerson, R. (1988). Indivisible labor, lotteries and equilibrium. Journal of Monetary Economics, 21, 3-16.

Rogerson, R., \& Wright, R. (1988). Involuntary unemployment in economies with efficient risk sharing. Journal of Monetary Economics, 22, 501-515.

Rotemberg, J., \& Woodford, M. (1996). Real-business-cycle models and the forecastable movements in output, hours, and consumption. American Economic Review, 86, 71-89.

Vasilev, A. (2009). Business cycles in Bulgaria and the Baltic countries: An RBC approach. International Journal of Computational Economics and Econometrics, 1(2), 148-170.

Vasilev, A. (2015a). Welfare effects of flat income tax reform: The case of Bulgaria. Eastern European Economics, 53(2), 205-220.

Vasilev, A. (2015b). Welfare gains from the adoption of proportional taxation in a general-equilibrium model with a grey economy: The case of Bulgaria's 2008 flat tax reform. Economic Change and Restructuring, 48(2), 169-185.

Vasilev, A. (2015c). Macroeconomic effects of public-sector unions. LABOUR, 29(2), 101-126.

Vasilev, A. (2016). Search and matching frictions and business cycle fluctuations in Bulgaria. Bulgarian Economic Papers BEP 03-2016, Center for Economic Theories and Policies, Sofia University St. Kliment Ohridski, Faculty of Economics and Business Administration, Sofia, Bulgaria.

Vasilev, A. (2017a). Business cycle accounting: Bulgaria after the introduction of the currency board arrangement (1999-2014). European Journal of Comparative Economics, 14(2), 197-219.

Vasilev, A. (2017b). A real-business-cycle model with efficiency wages and a government sector: The case of Bulgaria. Central European Journal of Economics and Econometrics, 9(4), 359-377.

Vasilev, A. (2017c). A real-business-cycle model with reciprocity in labor relations and fiscal policy: The case of Bulgaria, Bulgarian Economic Papers, BEP 03-2017, Center for Economic Theories and Policies, Sofia University St. Kliment Ohridski, Faculty of Economics and Business Administration, Sofia, Bulgaria.

Vasilev, A. (2017d). VAT evasion in Bulgaria: A general-equilibrium approach. Review of Economics and Institutions, 8(2), 2-17.

Westermark, A. (1999). A Model of Union Formation, Working Paper 1999:8, Department of Economics, Uppsala University.

Zanetti, F. (2007). A non-Walrasin labor market in a monetary model of the business cycle. Journal of Economic Dynamics and Control, 31, 2413-2437.

Publisher's Note Springer Nature remains neutral with regard to jurisdictional claims in published maps and institutional affiliations. 